\title{
Um estudo experimental sobre a funcionalidade comunicativa das imagens dinâmicas de manuais de produtos eletroeletrônico
}

\author{
An experimental study of the communicative functionality of dynamic images in \\ electronics products manuals.
}

\author{
Renata G. Wanderley
}

imagens dinâmicas, manuais de instrução, leitor

Essa pesquisa verificou a eficácia de imagens de manuais de eletroeletrônicos a partir dos seus usuários. Para isso, trabalhou o nível de compreensão das mensagens, identificando seus principais problemas. Observou o uso em si dos manuais e a preferência e utilização de suas informações. Como conclusão, discutiu a acessibilidade das informações das imagens e sua capacidade de transmissão de mensagens.

dynamic image, instruction manuals, reader

This research searched the effectiveness of images in manuals of electronic on the basis of its users. For this, it worked the level of understanding of the messages, identifying the main problems. It observed the use in itself of manuals and the preference and use of its information. As conclusion, argued the accessibility of the information of these images and its capacity of transmission of messages.

\section{Introdução}

Mais do que uma obra criativa as imagens dinâmicas instrucionais (imagens com representação de ações com função explicativa e educacional) representam e são um membro atuante e constante do sistema de aprendizagem, de informação, de comunicação. Nos manuais de instrução a força do conteúdo imagético dinâmico é ainda maior. O Direito do Consumidor e o Inmetro exigem uma representação imagética das ações a serem executadas para os produtos. O Código de Defesa do Consumidor diz que todos os produtos devem vir acompanhados de manual de instrução, em linguagem didática e com ilustrações.

A produção industrial vem lidando com constantes transformações e grandes avanços tecnológicos responsáveis em desenvolver novas funções para produtos já existentes e novos equipamentos com maior complexidade de operação. Os usuários desses produtos, porém, nem sempre estão capacitados a manusear ou operá-los de maneira segura e eficiente, necessitando de informações instrucionais para tanto, fornecidas, principalmente, pelos manuais de instrução. A expressão gráfica dessas instruções visuais, no entanto, nem sempre consegue auxiliar os usuários ao não explicitar claramente o procedimento a ser adotado (MORAES, MELO e MACÁRIO, 2003) ou não apresentar conteúdo informacional inadequado, tanto de forma de representação como de conteúdo conceitual, para expressar a ação a se

R. G. Wanderley. 2015. Um estudo experimental sobre a funcionalidade comunicativa das imagens dinâmicas de manuais de produtos eletroeletrônico. In: C. G. Spinillo; L. M. Fadel; V. T. Souto; T. B. P. Silva \& R. J. Camara (Eds). Anais [Pôster] do 7ํㅡㄴ Congresso Internacional de Design da Informação/Proceedings [Poster] of the 7th Information Design International Conference | CIDI 2015 Inlucher Design Proceedings, num.2, vol.2]. São Paulo: Blucher, 2015. ISSN 2318-6968, DOI 10.5151/designpro-CIDI2015-cidi_195 
realizar. Aprender a usar um produto com rapidez e facilidade depende tanto do design do manual quanto do produto. Os designers precisam organizar a estrutura dos textos em relação às dificuldades dos leitores, e não apenas pelo uso dos botões, caracteres, modos de exibição, e outros pontos ligados à engenharia (MORAES, NORONHA \& MARCÁRIO, 1996).

Muitas pesquisas focadas em imagens utilizadas em livros didáticos e em materiais de instrução vêm sendo desenvolvidas em caráter analítico e experimental como, por exemplo, Moraes, Melo e Macário (2003), Azevedo, Spinillo e Padovani (2005), Moraes (2006), Spinillo (2006). Estes já identificam inúmeros problemas estruturais, semânticos e pragmáticos nas imagens como inadequação do conteúdo imagético com o repertório intelectual e cultural do seu público-alvo, ambiguidade de ideias, conteúdo dependente do contexto de uso, representação gráfica diferente da usual, entre outros.

Considerando a importância da representação gráfica de ações para o processo instrucional, novas pesquisas sobre as imagens dinâmicas são importantes visando avaliar o conteúdo imagético, observar seus possíveis problemas comunicacionais e, por conseguinte, atenuar as deficiências informacionais das mensagens, sua compreensão e visualização. Deste modo, esta pesquisa, através de um experimental, procura identificar os principais problemas encontrados na expressão pictórica de ações e apresentar as algumas diretrizes para a elaboração de imagens dinâmicas mais eficientes para seus leitores. Assim sendo, observa-se a necessidade avaliativa da eficácia instrucional das imagens dinâmicas de manuais, já que conteúdos informacionais inadequados, tanto conceituais como gráficos, influenciam o entendimento das mensagens.

\section{0 experimento}

Essa pesquisa é uma continuação do estudo "As imagens dinâmicas dos manuais de produtos eletroeletrônicos conseguem instruir seu leitor a realizar a ação necessária?" de Wanderley (2009) cujo foco foi a análise teórica das ilustrações de manuais de instrução de produtos eletrônicos para a identificação de possíveis problemas estruturais de conteúdo e de forma de representação. Assim sendo, observa-se necessário para consolidar sua conclusão examinar quais os principais problemas contidos nas mesmas segundo resultados experimentais. Para isso, foi realizado um experimento exploratório como objetivo de verificar a compreensão das mensagens nas ilustrações e identificar as dificuldades ocorridas neste processo.

\section{O procedimento}

O experimento foi conduzido com cada participante particular e isoladamente. As ilustrações foram apresentadas individualmente a cada um, tendo este que descrever verbalmente as ações representadas na imagem isoladas e depois na página. As respostas foram registradas por escrito pelo pesquisador.

\section{O material}

Foram utilizadas 17 imagens dinâmicas de manuais de instrução de eletroeletrônicos (em tamanho5cm $\times 5 \mathrm{~cm}$ ) e17 cópias de suas páginas (em tamanho original) $O$ processo de escolha da amostragem foi probabilístico por aleatória simples. A figura 01 exemplifica 02 imagens individual trabalhadas e também na página completa.

Figura 1: Algumas imagens utilizadas no experimento (usado com a permissão de Wanderley
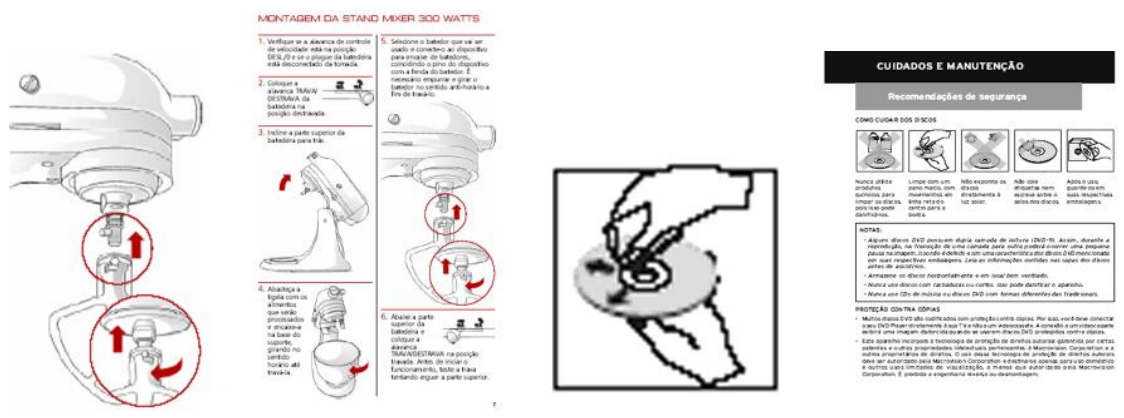

Anais [Pôster] do 7º Congresso Internacional de Design da Informação | CIDI 2015

Proceedings [Poster] of the 7th Information Design International Conference / IDIC 2015 


\section{Participantes}

10 usuários diretos dos produto eletroeletrônico específico. Eles se caracterizaram por ambos os sexos, com idades entre 21 a 50 anos e com formação a partir do fundamental II de escolas particulares.

\section{Discussão dos resultados}

Os dados foram trabalhados em dois momentos: (1) a definição do nível de compreensão de cada imagem para cada participante e (2) a discussão dos principais problemas das imagens demonstrados nas respostas a elas pelos leitores.Cada resposta de cada participante foi analisada individualmente em relação ao seu conteúdo geral (a identificação da mensagem base) e às informações detalhadas (cada elemento conceitual e gráfico).

A fase 01 teve como base de análise os parâmetros: (a) compreendeu, quando identifica a ação em si (nomeando ou demonstrando percebê-la) e suas partes; (b) compreendeu parcialmente, quando compreende a ação em si, mas não detalha as informações ou compreende a ação de forma pouco decisiva, mas compreende suas partes; e (c) não compreendeu, quando não identifica a ação nem suas partes. Eles foram aplicados no domínio de mensagem geral compreendida.

Já na fase 02 a avaliação se embasou nos em parte dos parâmetros do artigo " imagens dinâmicas em níveis semióticos e fatores visuais" de Wanderley (2011): (1) Unidade semântica, (2) Unidade sintática, (3) Localização semântica, (4) Localização sintática, (5) Temporalidade semântica, (6) Temporalidade sintática, (7) Titulação semântica (8) Titulação sintática. O nível pragmático não é trabalhado na pesquisa pois, ao representar a participação do leitor na identificação das informações,é redundante. Unidade corresponde a definição de cada elemento individual e a titulação a identificação da ação em si. A temporalidade significa a relação temporal enquanto a localização a relação espacial entre as informações. Semântico se estrutura no conteúdo conceitual e o sintático no conteúdo gráfico.

\section{Resultados Gerais}

A maioria das imagens dinâmicas tem compreensão parcial por permitir ou a compreensão da ação geral, mas não o entendimento das informações necessárias a sua realização, como outras ações ou movimentos; ou a não indicação da ação em si, mas a compreensão de suas partes. Essa observação é importante, pois para o leitor realmente conseguir entender e realizar as ações necessárias aos produtos é fundamental tanto perceber a ação final como todas as suas etapas, com seus participantes, movimentos, trajetórias e frequências. Apenas $26,32 \%$ dos leitores conseguiram identificar a mensagem corretamente, definindo a ação e todas as suas informações relevantes. Assim, apenas esses, possivelmente, conseguirão executar a ação da forma esperada e indicada. E 31,58\% das imagens não conseguiram se comunicar com seu leitor, pois 5,26\% necessitaram das informações verbais e em $26,32 \%$ a mensagem não foi compreendida em nenhum nível. A tabela 1 apresenta os resultados da primeira fase.

Tabela 1: Resultado da fase 01

\begin{tabular}{l|l} 
Nível de compreensão & Percentagem \\
\hline Compreendeu & $26,32 \% ;$ \\
\hline $\begin{array}{l}\text { Compreendeu parcialmente } \\
\text { (compreendeu a ação, mas não a detalhou) }\end{array}$ & $38,95 \% ;$ \\
\hline $\begin{array}{l}\text { Compreendeu parcialmente } \\
\text { (não nomeou a ação, mas compreendeu as partes) }\end{array}$ & $7,37 \% ;$ \\
\hline Compreendeu apenas com o texto & $5,26 \% ;$ \\
\hline Não compreendeu & $26,32 \%$ \\
\hline
\end{tabular}

Mesmo tendo importância para a conceituação, caracterização e especificação de ações, as unidades conceituais das ações são pouco trabalhadas nas respostas dos leitores diante das imagens dinâmicas. Em $85,26 \%$ delas a unidade semântica é problemática, tendo conteúdo incompleto em nível significativo (76,84\%). Muitas das informações conceituais, com 
exceção dos participantes ambiente, paciente e agente, são negligenciadas, nem apresentadas nem percebidas; ou têm definições incorretas. Como causa desta problemática se percebe a pouca atuação eficaz das formas de representação empregadas para expressar esses elementos conceituais $(29,47 \%)$. Esses recursos demonstram ser principalmente não compreendidos $(23,16 \%)$, mal empregados $(25,26 \%)$ e inadequados $(18,95 \%)$.

O destaque de problemas nas unidades perde força quando analisado a variável titulação semântica. Mesmo não assimilando ou indicando os elementos conceituais nas respostas, os leitores expressam literalmente ou demonstram compreender a ação em $65,26 \%$. Ainda, contudo, é relevante a dificuldade de identificação da ação final $(34,74)$, já que elas não são apresentadas em 18,95\% e há problema de significação ou nomeação em $6,32 \%$. A capacidade informativa dos meios gráficos para a ação em si parece ser mais significativa do que para as unidades, pois em também $65,26 \%$ os recursos empregados trabalham para a definição e compreensão da ação geral. Apesar disso, a ineficiência das informações gráficas em 34, 74\% é expressiva, pois a identificação da ação é a conclusão da mensagem. O uso de recursos mal empregados, insuficientes ou inadequados ainda é comum, bem como de recursos não compreendidos e nem trabalhados.

A temporalidade é uma informação com comportamento particular nas respostas dos leitores. Poucos a apresentam na mensagem (52,63\%), minimizando sua importância enquanto informação fundamental para a ação. Quando a expressam são incorretas ou insuficientes. Isso demonstra que ou essa informação não é percebida ou está sendo negligenciada pelos leitores ou pelas imagens (seus criadores). Os $43,16 \%$ de compreensão do conteúdo temporal é mais uma consequência da não caracterização desta informação para a ação, ou melhor, para o momento da ação ou da própria imagem, do que da definição do sequenciamento dos acontecimentos na resposta á imagem. Como com acontecem com as informações conceituais de temporalidade, as gráficas demonstram também serem problemática em mesmo nível básico $56,84 \%$, tendo desde recursos inadequados, a incompreendidos e insuficientes. Diferentemente, contudo, a sua atuação eficaz nos $43,16 \%$ é legítima. Além de tudo isso, diante de uma percentagem relevante da inexistência de informações temporais, a análise da temporalidade sintática é complexa por falta de dados informativos.

Por fim, o relacionamento espacial das informações é a característica da ação com menos expressividade, pois em $85,26 \%$ são percebidas, compreendidas ou demonstram ser uma informação irrelevante. Com isso, os recursos visuais de localização ou trabalham com eficiência ou não dificultam a mensagem.

A tabela 2 detalha o diagnóstico da problemática da compreensão das ilustrações individuais e na página original.

Tabela 2: Diagnose problemática

\begin{tabular}{|c|c|c|}
\hline $\begin{array}{l}\text { Elementos / } \\
\text { nível }\end{array}$ & Semântico & Sintático \\
\hline Unidade & $\begin{array}{l}\text { Sem problema (14,74\%) } \\
\text { Problemática (85,3\%): } \\
\text { - Informações incompreendidas } \\
\text { (1,2\% e } 1 \%) \\
\text { - Problema de significação (4,9\% e } 4,2 \%) \\
\text { - Dificuldade de visualização (1,2\% e 1,1\%) } \\
\text { - Dificuldade de individualização das } \\
\text { unidades (3,7\% e } 3,2 \%) \\
\text { - Informação ausentes (12,4\% e 10,5\%) } \\
\text { - Informações não percebidas } \\
\text { (6,1\% e 5,3\%) } \\
\text { - Informações incompletas (90,1\% e } 76,8 \%) \\
\text { - Informações incorretas }(9,9 \% \text { e } 8,4 \%) \\
\text { - Informações inadequadas }(2,5 \% \text { e } 2,1 \%)\end{array}$ & $\begin{array}{l}\text { Sem problema ( } 28 \text { / 29,47\%) } \\
\text { Problemática ( } 70,5 \%) \text { : } \\
\text { - Recursos pouco trabalhados (4,5\% e } \\
3,2 \%) \\
\text { - Recursos não trabalhados }(25,4 \% \text { e } \\
18 \%) \\
\text { - Recursos incompreendidos(32,8\% e } \\
23,2 \%) \\
\text { - Informações incompreendidas (3\% e } \\
2,1 \%) \\
\text { - Dificuldade de individualização (1,4\%) } \\
\text { - Recursos inadequados ( } 26,87 \% \text { e } \\
18,9 \%) \\
\text { - Recursos mal empregados (35,8\% e } \\
25,3 \%) \\
\text { - Recursos insuficientes (31,3\% e } \\
22,1 \%) \\
\text { - Problemas com recursos básicos } \\
(1,4 \%)\end{array}$ \\
\hline
\end{tabular}




\begin{tabular}{|c|c|c|}
\hline Localização & $\begin{array}{l}\text { Sem problema (81 / 85,26\%) } \\
\text { Problemática (14,7\%:) } \\
\text { - Informação não apresentada (14,7\%:) }\end{array}$ & $\begin{array}{l}\text { Sem problema }(81 / 85,26 \%) \\
\text { Problemático }(14,7 \%)\end{array}$ \\
\hline Temporalidade & $\begin{array}{l}\text { Sem problema (41 / 43,16\%) } \\
\text { Problemática (56,8\%): } \\
\text { - Informação incompreendida (1,9\% e 1,1\%) } \\
\text { - Informação não apresentada (92,6\% e } \\
52,6 \%) \\
\text { - Informação incorreta (7,4\% e 4,2\%) } \\
\text { - Informações incompletas (1,9\% e 1,1\%) }\end{array}$ & $\begin{array}{l}\text { Sem problema (41/43,16\%) } \\
\text { Problemática ( } 56,8 \%) \text { : } \\
\text { - Recursos não percebidos (3,7\% e } \\
2,1 \%) \\
\text { - Recursos incompreendidos }(1,9 \% \text { e } \\
1,1 \%) \\
\text { - Recursos não trabalhados }(1,9 \% \text { e } \\
1,05 \%) \\
\text { - Recursos inadequados }(5,6 \% \text { e } 3,2 \%) \\
\text { - Recursos mal empregados }(3,7 \% \text { e } \\
2,1 \%) \\
\text { - Recursos insuficientes( } 1,9 \% \text { e 1,1\%) } \\
\text { - Recurso incompreendido(1,9\% e } \\
1,1 \%)\end{array}$ \\
\hline Titulação & $\begin{array}{l}\text { Sem problema (62 / 65,26\%) } \\
\text { Problemática (34,74\%): } \\
\text { - Informação incompreendida(24,2\% e } \\
8,4 \%) \\
\text { - Problema de significação (18,2\% e 6,3\%) } \\
\text { - Informação não apresentadas (54,6\% e } \\
19 \%) \\
\text { - Informações insuficientes (6,1\% e 2,1\%) } \\
\text { - Informação incompleta (3,0 e 1,1\%) } \\
\text { - Informação incorreta }(12,1 \% \text { e } 4,2 \%) \\
\text { - Informação insegura }(3,0 \text { e } 1,1 \%)\end{array}$ & $\begin{array}{l}\text { Sem problema (62 / 65,26\%) } \\
\text { Problemática (34,7\%): } \\
\text { - Recursos não percebidos }(36,4 \% \text { e } \\
12,6 \%) \\
\text { - Recursos incompreendidos }(15,2 \% \text { e } \\
5,3 \%) \\
\text { - Recursos não trabalhos }(6,1 \% \text { e } \\
2,1 \%) \\
\text { - Recursos inadequados }(36,4 \% \text { e } \\
12,6 \%) \\
- \text { Recursos mal empregados }(30,3 \% \text { e } \\
10,5 \%) \\
- \text { Recursos não trabalhos }(6,1 \% \text { e } \\
2,1 \%) \\
- \text { Recursos insuficientes }(18,2 \% \text { e } \\
6,3 \%)\end{array}$ \\
\hline
\end{tabular}

\section{Conclusão}

Os próprios leitores das imagens dinâmicas demonstram que a compreensão de suas mensagens é frágil. Esta, mesmo tendo um nível de não compreensão não muito elevado, tem semelhante força de compreensibilidade, fato que torna problemático um número significativo de imagens. A parcialidade da compreensão, independente da especificidade, pode evidenciar uma incapacidade de acessibilidade às informações na imagem por parte dos leitores. As imagens parecem não conseguir dialogar bem com os leitores, pois eles percebem o assunto (a ação geral), mas não entendem ou recebem o processo (as partes).

Tanto os aspectos sintáticos como, e principalmente, os conceituais demonstram necessitarem ser mais bem trabalhados. A consciência das necessidades informacionais para a representação completa das mensagens parece anêmica. Conteúdos incompletos e informações não apresentadas se destacam em todos os fatores visuais em ambos os níveis semióticos, dificultando, ou até impossibilitando, a transmissão das mensagens por carência de informações. Recursos e informações inadequados e mal empregados também fortalecem essa deficiência ao possibilitarem interpretações diferentes, distantes, da mensagem.

O não detalhamento da mensagem, a não caracterização das unidades do processo da ação representada tem a força mais relevante para a dificuldade na compreensão total desta mensagem. Mesmo compreendendo a importância da percepção do todo (da ação global) para a eficácia da mensagem, o alcance destacado da compreensão parcial demonstra uma negligência expressiva na variável unidade, o conteúdo conceitual destrinchado das ações, e em menor força, nos aspectos gráficos utilizados para representá-las. 
Além da unidade, outra informação essencial para ações vem sendo descuidada: a temporalidade. A relação temporal entre os elementos da imagem vem sendo trabalhada com pouca relevância, muitas vezes ignoradas, tanto no aspecto semântico como no sintático.

Já o relacionamento espacial entre as componentes da imagem tem clareza de expressão ou pelo menos não interferem com relevância na mensagem. A percepção da ação geral na titulação também parece trabalhar com resultado positivo, embora por sua importância na comunicação, ainda tenha destaque no processo de não compreensão.

Enfim, esta discussão ainda e também questiona a eficácia das representações gráficas de ações dos manuais de instrução de produtos eletroeletrônicos diante de uma abordagem experimental. Assim, essa pesquisa observa a necessidade de redesign dessas imagens dinâmicas, tendo mais atenção nos elementos conceituais das ações e nas suas características temporais. E a constante e cuidadosa preocupação com os leitores, tanto em relação ao conteúdo conceitual quanto gráfico, igualmente qualifica as imagens e deve ser base para o processo criativo das mensagens.

\section{Referências}

AZEVEDO, E. R.; SPINILLO, C. G. ; PADOVANI, S. 2005. Advertências em manuais de instrução de telefones celulares. In: $3^{\circ}$ Congresso Internacional de Pesquisa em Design. Anais do $3^{\circ}$ Congresso Internacional de Pesquisa em Design. Rio de Janeiro: ANPEDAssociação Nacional de Pesquisa em Design.

INMETRO. 2009. Código de Defesa do Direito do Consumidor. Presidência, 2009. Disponível em: www.presidencia.gov.br/ccivil_03/Leis/L8078.htm . Acesso em: 15 jan.2010.

MORAES, A. NORONHA,C.; MACÁRIO, M. 1996. Ergonomia, usabilidade e qualidade de produtos: conforto e segurança dos usuários, defesa do consumidor. In: P\&D Design. Anais do P\&D Design. Rio de Janeiro, Associação de Ensino de Design do Brasil. pp. 11-21.

MORAES, A.; MELO, C. N. de; MACÁRIO, M.2003. A ergonomia e usabilidade -segurança e conforto dos usuários de produtos domésticos considerados perigosos: manuais de instrução. In: $3^{\circ}$ Congresso Internacional de Ergonomia e Usabilidade de Interfaces Humano-Tecnologia. Anais do $3^{\circ}$ Congresso internacional de Ergonomia e Usabilidade de Interfaces Humano-tecnologia. v. 1. p. 6-6.

MORAES, A. M. 2006. Ergonomia e usabilidade: analisando dois manuais de instrução de produtos domésticos através do método da avaliação cooperativa, com mulheres de 20 a 35 anos. In: ABERGO 2006 | 140 Congresso Brasileiro de Ergonomia. Anais do ABERGO | 14은 Congresso Brasileiro de Ergonomia. Curitiba : ABERGO, v. 1.

SPINILLO, C. G.; PITELLA, T. V. B. ; KIMURA, I. 2006. Material instrucional para produtos DIYDo It Yourself (Faça - Você - Mesmo ) em habitação de interesse social: estudo de instruções visuais sobre sistema de cobertura. In: ABERGO 2006 | 140 Congresso Brasileiro de Ergonomia. Anais do ABERGO 2006 | 14ํㅡㄹ Congresso Brasileiro de Ergonomia. Curitiba: ABERGO. v. 1.

WANDERLEY, R.G. 2009. As imagens dinâmicas dos manuais de produtos eletroeletrônicos conseguem instruir seu leitor a realizar a ação necessária?. In: VI Congresso Internacional de Design da Informação. Anais do IV Congresso Internacional de Design da Informação. Rio de Janeiro: SBDI.

WANDERLEY, R.G. 2011. Imagens dinâmicas em níveis semióticos e fatores visuais: Um instrumento de análise. In: VI International Congress in Design Research. Anais do VI International Congress in Design Research. Lisboa: CiAUD - Universidade Técnica de Lisboa.

\section{Sobre a autora}

Renata Garcia Wanderley, doutora, UFPE, Brasil, <renatagw@hotmail.com> 